\title{
Breeding for management adaptation in perennial ryegrass (Lolium perenne L). II. Genetic variability and heritability of leaf morphogenesis components
}

\author{
M Ghesquière *, L Hazard, M Betin \\ INRA, Station d'Amélioration des Plantes Fourragères, F86600 Lusignan, France
}

(Received 15 November 1993; accepted 14 April 1994)

\begin{abstract}
Summary - A space-limited experimental design was used for estimating the genetic parameters of growth components in Lolium perenne. These parameters might be taken into account in breeding for yield under a given management. From 58 half-sib families derived from a single polycross, the morphogenesis of 3 successive leaves on 1 tiller of 20 individuals per family was recorded 3 times a week in the spring. Phyllochron, duration of leaf elongation and adult leaf length were measured, and the leaf elongation rate and the mean number of growing leaves per tiller were estimated. Leaf length and elongation rate were found to be highly correlated and showed a genetic variability and a narrowsense heritability that were definitely higher than phyllochron and duration of leaf elongation. Compared with controls, the progenies indicated an extended genetic variability of morphogenetic traits, mainly towards to genotypes with short leaves and/or rapid phyllochron (but to a lesser extent). Leaf length therefore appeared as the morphogenetic trait that could be most modified through selection. This has been used as a selection criterion in breeding for high productivity under infrequent cutting. Conversely, no morphogenetic trait such as phyllochron, which is assumed to control yield under frequent cutting, responds so effectively to selection, which led us to propose that selecting for short-leaved genotypes could be an alternative approach that should be investigated.
\end{abstract}

Lolium perenne $=$ perennial ryegrass $/$ heritability $/$ leaf morphogenesis $/$ breeding method $/$ cutting frequency

Résumé - Amélioration de l'adaptation au mode d'exploitation chez le ray-grass anglais (Lolium perenne $L$ ). II. Variabilité génétique et héritabilité des composantes de la morphogénèse foliaire. Un dispositif expérimental réduit a été utilisé pour estimer les paramètres génétiques des composantes de la morphogenèse chez le ray-grass anglais et comment ceux-ci pourraient être pris en compte en sélection pour améliorer la productivité dans un système d'exploitation donné. À partir de 58 familles de demi-frères issues d'un polycross, la morphogenèse de 3 feuilles successives a été enregistrée 3 fois par semaine au printemps sur une talle chez 20 individus par famille. Le phyllochrone, la durée d'allongement des feuilles et leur longueur finale ont été déterminés et ont permis d'estimer la vitesse d'allongement ainsi que le nombre moyen de feuilles en croissance par talle. Une corrélation étroite a été mise en évidence entre longueur des feuilles et vitesse d'allongement, qui ont montré également une variabilité génétique ainsi qu'une héritabilité au sens étroit nettement supérieures à celles du phyllochrone et de la durée d'allongement. En comparaison des variétés témoins, les descendances se sont caractérisées par un élargissement de la variabilité génétique des caractères de la morphogénèse, en particulier dans le sens de génotypes à petites feuilles et/ou phyllochrone rapide dans une moindre mesure. La longueur des feuilles apparaît ainsi comme le caractère le plus susceptible d'être modifié par sélection a pu être plus ou moins directement utilisé comme critère de sélection pour améliorer le rendement en système de fauche. Inversement, aucun caractère pressenti déterminant pour améliorer le rendement en coupes fréquentes, tel le phyllochrone, ne semble être aussi manipulable par sélection ; ce qui amène à proposer qu'une sélection pour des génotypes à feuilles courtes pourrait être une solution qui mériterait d'être testée expérimentalement.

Lolium perenne = ray-grass anglais / héritabilité / morphogénèse foliaire / méthode de sélection / fréquence de coupe

\footnotetext{
* Correspondence and reprints
} 


\section{INTRODUCTION}

In a previous paper, we reported that yield of natural populations and varieties in Lolium perenne was negatively correlated between 2 contrasting cutting frequencies simulating either silage or continuous grazing management (Hazard et al, 1994). Compared with progenies, it appeared that breeding led to varieties that were more adapted under infrequent than frequent cutting and that breeding for specific management, particularly for a higher productivity under frequent defoliation, should be considered.

Rhodes (1973) showed that productivity of clonal swards with contrasting morphogenetic traits was closely related to cutting frequency. Sugiyama (1987) also confirmed these relationships from natural populations and varieties in tall fescue leading to a definition of ideotype according to management: sward with few large tillers for infrequent cutting versus sward with many small tillers for frequent cutting. As regards breeding for specific management, Nelson and Sleper (1981) carried out effective divergent selection for leaf area expansion rate, which did not lead to the expected effect on yield under contrasting cutting frequencies. The population selected for high leaf area expansion rate remained the most productive at both managements (Sleper and Nelson, 1989). The frequent cutting management that they applied was eventually not drastic enough to point out the potentially higher productivity of the low selected population under these conditions.

If definition of ideotypes adapted to specific management does not seem too ambiguous, the breeding method for this objective remains much less easy to clarify. One difficulty is that definition of ideotypes is based on traits characterized by sward conditions, such as tiller density, which are also highly susceptible to environmental interactions. However, breeding requires that at least some selection can be done among single individuals from a large population and just in one standard environment. Even though we could expect some relationships between morphogenesis of single individuals selected in spaced conditions and growth rate of their progenies in sward, the efficiency of such a selection could be highly restricted by practical difficulties such as the fact that assessment of morphogenetic traits among numerous individuals is time-consuming and expensive.

The objective of this paper is therefore to test the feasibility of this approach and to provide genetic parameters of morphogenetic traits (fig 1) in order to determine which trait could be introduced in breeding procedures to significantly modify morphogenesis and, hopefully, the productivity under appropriate management.

\section{MATERIALS AND METHODS}

Fifty-eight half-sib families were observed. They were obtained by polycrossing plants selected from natural late-flowering French populations of Lolium perenne (Charmet et al, 1990) as part of the INRA-ACVF cooperative programme on the study of perennial ryegrass germplasm in France supported by the Ministère de l'Agriculture. Two contrasting control varieties, 'Vigor' and 'Preference', were also included.

After germination in Petri dishes, 20 seedlings of each family were planted individually in October in small pots $(5 \mathrm{~cm}$ diameter $\times 5 \mathrm{~cm}$ depth) of sterilized compost. On 25 January (2-3-tiller stage), the pots were transferred to tables in open conditions and arranged in a random design of 20 blocks of $6 \times 10$ pots each in such a way that one single individual per family was assigned to each block. On 15 March, one main tiller per plant was marked by a plastic ring and all the other tillers were removed. The tip of the last growing leaf of each marked tiller was cut on 30 March, thus allowing us to easily record the growth of the next leaves. From 1st April to 18 May, all 1200 plants were individually surveyed 3 times a week. The appearance date of 4 new leaves was recorded as well as the date of ligule emergence of the first 3 leaves. Finally, the lamina length of the first 3 leaves was measured from ligule to tip. All plants remained vegetative for the entire recording period, which thus allowed us to estimate leaf elongation rate without any interference of the stem elongation inside the sheath.

Leaf appearance rate was expressed as the average number of days between lamina emergence of 2 successive leaves, ie as a phyllochron (PHY). Considering that ligule emergence indicated the end of lamina elongation, duration of leaf elongation (LED) was calculated as the average number of days between the lamina and the ligule appearance of each

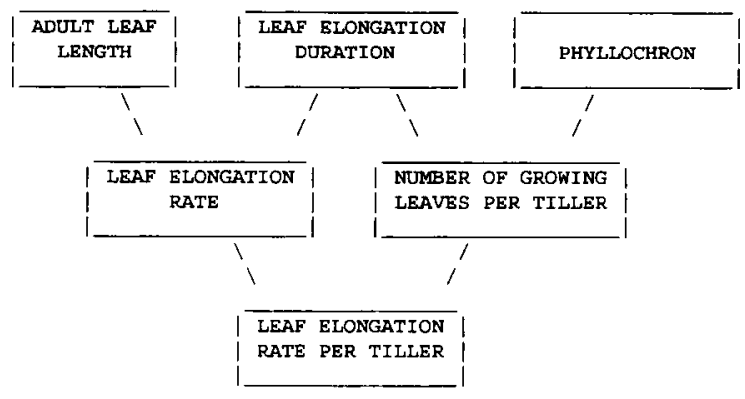

Fig 1. Relationships between observed (upper row) and estimated (below) leaf morphogenesis components. 
leaf; leaf elongation rate (LER) was estimated as the ratio between adult leaf length ( $A L L$ ) and $L E D$. Because of the overlapping growth of successive leaves on a tiller, the average number of growing leaves (NGL) was calculated as the ratio between LED and PHY. Finally, the rate of leaf elongation per tiller (LERt) was estimated as the product of LER by NGL.

A multivariate analysis of variance was performed on all 6 growth components assuming random genotypic effects for estimating genetic variances and covariances. As an environmental effect was detected from the outside 10-plant rows, a sub-block within block effect was included in the statistical model. Thus, correlations between sub-blocks were used as environmental correlations for comparison with genetic correlations. Narrow-sense heritability was estimated as $h^{2}=4 \sigma_{g}^{2} / \sigma_{p}^{2}$ where $\sigma_{p}^{2}=\sigma_{g}^{2}+\sigma_{e}^{2}$ and $\sigma_{p}^{2}, \sigma_{g}^{2}, \sigma_{e}^{2}$ were the phenotypic, genetic, and error variances, respectively. Coheritability between pairs of traits was calculated as $h^{2} x y=r_{\mathrm{g}} h_{x} h_{y}$ where $r_{\mathrm{g}}$ was the genetic coefficient of correlation between traits $x$ and $y$, and $h_{x}$ and $h_{y}$ were the square roots of the heritability of each trait. The expected efficiency of direct versus indirect selection was therefore estimated as $R=i \bullet h^{2} \bullet \sigma_{\mathrm{p}}$ and $C R_{y}=i \bullet h^{2} x y \bullet \sigma_{p y}$, where $i$ was the intensity of selection in phenotypic standard deviation units $(i=2.063$ for a $5 \%$ rate of mass selection), and responses were then weighted by the mean to be compared among traits (Falconer, 1981).

\section{RESULTS}

The first new leaf appeared on the average $6.4 \mathrm{~d}$ after the beginning of the experiment, ie half a phyllochron if one considers that the last appeared leaves, randomly cut as control, were half-grown on average. As expected, the second leaf emerged roughly after a time twice as long
(14.3 d). Thereafter, the sequence of morphogenetic events occurred steadily: before each leaf ended its own growth a new leaf emerged so that during a short time, more than one single leaf per tiller was growing.

Analysis of variance showed significant genetic effects for all morphogenetic traits (table I) with both controls tending to range either above or below the overall means (table II). The controls 'Preference' and 'Vigor' did not differ significantly from each other for any trait but showed overall longer phyllochron, larger leaf size and higher leaf elongation rate. Leaf length and elongation rate had larger genotypic coefficients of variation than phyllochron, duration of leaf elongation and number of growing leaves. Most of the error coefficients of variation were higher than $10 \%$ but, given the correct level of control of the environmental variability, the sub-block effects were only significant in a few cases; this can be attributed to large within-family genetic variability.

If we consider the interrelationships between traits as described in figure 1, adult leaf length and leaf elongation rate were found to be highly correlated but not duration of leaf elongation (table III). Similarly, the estimated number of growing leaves was significantly more correlated $(P<0.01)$ with duration of leaf elongation than to phyllochron. Finally, the resulting leaf elongation rate per tiller was found more highly correlated to either LER or ALL than to NGL. Overall, phyllochron appeared as a genetically very independent trait among the growth components surveyed. Environmental correlations gave a similar pattern, ie with no or very few negative correlations, except that PHY and LED seemed to show

Table I. Mean and range (95\% confidence interval) of leaf morphogenesis components among 58 half-sib progenies and 2 controls 'Preference'. and 'Vigor'.

Mean 'Preference' 'Vigor' Range

Phyllochron (PHY) (d)

Adult leaf length $(A L L)(\mathrm{mm})$

Leaf elongation duration (LED) (d)

Number of growing leaves per tiller (NGL)

Leaf elongation rate $(\mathrm{LER})(\mathrm{mm} / \mathrm{d})$

Leaf elongation rate per tiller (LERt) $(\mathrm{mm} / \mathrm{d})$
10.38

10.39

91.52

14.70

1.42

6.27

8.89
97.41

14.91

1.44

6.58

9.48
10.68

$9.81-10.95$

$77.23-105.81$

93.19

14.54

$13.66-15.74$

$1.33-1.51$

5.38-7.16

$7.47-10.31$ 
Table II. Analysis of variance of leaf morphogenesis components.

\begin{tabular}{llllll}
\hline & F Block & S/Block & Half-sib family & CVe $(\%)$ & CVg $(\%)$ \\
\hline PHY & 1.210 & 0.918 & $1.477^{\star}$ & 9.9 & 2.7 \\
ALL & 0.843 & $2.518^{\star \star}$ & $4.897^{\star \star}$ & 15.8 & 7.8 \\
LED & 0.537 & 1.128 & $1.799^{\star \star}$ & 11.8 & 3.5 \\
NGL & 1.026 & 1.484 & $2.979^{\star \star}$ & 8.6 & 3.3 \\
LER & 1.105 & 1.466 & $3.610^{\star \star}$ & 16.8 & 7.1 \\
LERt & 1.071 & $2.306^{\star \star}$ & $4.103^{\star \star}$ & 17.6 & 8.0 \\
\hline
\end{tabular}

${ }^{*} P=0.05 ;{ }^{\star \star} P=0.01 . \mathrm{CV}_{\mathrm{e}}$ and $\mathrm{CV}_{\mathrm{g}}$ are the error and genotypic coefficients of variation, respectively.

some physiological balancing as they were significantly correlated. A shorter phyllochron in the more actively growing sub-blocks tended to be associated with a decreasing duration of leaf elongation.

Narrow-sense heritabilities ranged widely among components from $9.6 \%$ (PHY) to $67.4 \%$ (ALL) with high estimates for LER and LERt (table IV). Although NGL was estimated by 2 low heritable single components (PHY and LED), the heritability of NGL reached $37.4 \%$. Coheritabilities showed that selection for ALL would lead to a larger associated response of LER than selection for LED, even higher than the direct response of LER. Similarly, selection for LED should be more effective than PHY for increasing NGL but no better than direct selection for NGL. LERt resulted from a combination of all traits, but the most effective trait to be selected for modifying indirectly LERt was ALL.

When expected response was estimated using phenotypic standard deviation and was weighted by the mean of the traits, the ranking of direct response remained the same as when they were based on heritability (table V). However, the direct response of PHY, LED and NGL was even reduced to some extent because of low relative phenotypic variability of these traits, which also explained the overall asymmetry of the correlated responses.

Table III. Genetic (below diagonal) and environmental correlations (above) between leaf morphogenesis components.

\begin{tabular}{lllllll}
\hline & $P H Y$ & ALL & LED & NGL & LER & LERt \\
& - & 0.042 & $0.607^{\star \star}$ & -0.213 & -0.312 & -0.328 \\
ALL & 0.139 & - & $0.527^{\star}$ & $0.616^{\star \star}$ & $0.855^{\star \star}$ & $0.926^{\star \star}$ \\
LED & 0.112 & $0.553^{\star \star}$ & - & $0.643^{\star \star}$ & 0.023 & 0.288 \\
NGL & $-0.476^{\star \star}$ & $0.409^{\star \star}$ & $0.819^{\star \star}$ & - & 0.337 & $0.680^{* \star}$ \\
LER & 0.124 & $0.941^{\star \star}$ & 0.238 & 0.138 & - & $0.916^{\star \star}$ \\
LERt & -0.075 & $0.978^{\star \star}$ & $0.536^{\star \star}$ & $0.519^{\star \star}$ & $0.918^{\star \star}$ & - \\
\hline
\end{tabular}

${ }^{*} P=0.05 ;{ }^{*} P=0.01$. 
Table IV. Narrow-sense heritability (diagonal) and coheritability of leaf morphogenesis components.

\begin{tabular}{lrlllll}
\hline & PHY & ALL & LED & NGL & LER & LERt \\
\hline PHY & 0.096 & & & & \\
ALL & 0.035 & 0.674 & & & \\
LED & 0.014 & 0.182 & 0.160 & & \\
NGL & -0.090 & 0.205 & 0.200 & 0.374 & & \\
LER & 0.027 & 0.534 & 0.066 & 0.058 & 0.478 & \\
LERt & -0.017 & 0.599 & 0.160 & 0.237 & 0.473 & 0.556 \\
\hline
\end{tabular}

Table V. Expected direct (diagonal) and associated (below and above) responses (\% of mean) after $5 \%$ of mass selection for increasing any of the 6 leaf morphogenesis components.

\begin{tabular}{lrrrrrr}
\hline Selection & PHY & ALL & LED & NGL & LER & LERt \\
\hline & & & & & & \\
PHY & 2.0 & 0.7 & 0.3 & -1.9 & 0.6 & -0.4 \\
ALL & 0.2 & 24.1 & 6.5 & 7.3 & 19.1 & 21.4 \\
LED & 0.3 & 4.5 & 4.0 & 5.0 & 1.6 & 4.0 \\
NGL & -1.7 & 3.8 & 3.7 & 7.0 & 1.1 & 4.4 \\
LER & 1.0 & 19.7 & 2.4 & 2.1 & 17.6 & 17.4 \\
LERt & -0.7 & 23.5 & 6.3 & 9.3 & 18.5 & 21.8 \\
\hline
\end{tabular}

\section{DISCUSSION}

The results showed that leaf length had the largest genetic variability among the 6 morphological characters surveyed and was the most heritable trait and highly correlated with leaf elongation rate. Moreover, when compared with the controls, the progenies indicated that there was an extended genetic variability towards genotypes with short leaves and/or rapid phyllochron.

Intra-population variability and relationships between growth components were described in tall fescue by Nelson and Sleper (1977). Furthermore, Sleper et al (1977) found from diallel that general combining ability of leaf area expansion rate and leaf elongation rate in tall fescue was far higher than specific combining ability with heritability ranging from 26 to $54 \%$. From experimental populations of tall fescue selected for increasing leaf area expansion rate (Nelson and Sleper, 1981) and using recurrent restricted phenotypic selection (Burton, 1974), analysis of the 3rd and 5th cycle showed that selection was effective in both directions in modifying leaf elongation rate (Reeder et al, 1984).
Cooper and Edwards (1961) found that most leaf development traits in $L$ perenne also had high genetic variability and heritability. Response to experimental selection for increasing either phyllochron or leaf size later confirmed that it was possible to modify morphogenesis significantly in $L$ perenne but, in both cases, with strong negative correlation between the 2 components (Edwards and Cooper, 1963).

The lack of significant negative correlations we reported between PHY and either ALL or LER might be attributed partly to the reduced vegetative development of plants. The space-limited experimental design used and the early period in spring in which plants were recorded, might have restricted the growth rate to some extent. These conditions allowed us to easily record many plants and to avoid any interference between vegetative growth and heading. Moreover, better growing conditions would have led to even worse discrimination between families as far as PHY and LED were concerned, because of large error variances and the practical impossibility of increasing the frequency of recording. The estimation of the genetic correlations and consequently, the expected associated response to 
selection therefore need to be carefully considered. The range of genetic variability and heritability among traits can be considered as reliable as well as the conclusions regarding the efficiency of direct selection for either single component.

Provided that morphogenetic traits are assessed at an early stage to avoid too much restriction of growth, this limited experimental design could be useful for selection prospects, but it was impossible to consider them under the usual conditions of nursery in the field. Following selection for morphogenetic traits, further breeding procedures as disease-tolerance tests could also be applied to the plant material grown in the same design. Moreover, controlling the temperature in the growth room should improve the efficiency of selection for morphogenetic traits.

As the progenies are derived from a large sample of independent natural populations after one generation of polycrossing, heritability and response to selection might be overestimated if genetic effects resulted mainly from linkage disequilibrium (Wrike and Weber, 1986). This emphasizes that leaf length should be a morphogenetic trait (if not the only one) that can be best modified through selection. It is known that leaf length is positively correlated with yield under infrequent cutting (Nelson and Sleper, 1977; Horst et al, 1978) and our results confirmed that it has probably been associated more or less deliberately by plant breeders in selecting for increasing yield under this management (Hazard et al, 1994). The idea that selecting leaf length inversely may eventually increase yield under frequent cutting is still hypothetical and needs to be checked. Whatever the underlying control of growth in a frequently cut sward, mass selection of short-leaved genotypes would imply some specific methodological difficulties as there could be confusion between individuals with a real high tillering potential and those which are just poorly vigorous. Furthermore, the overall effect tend to decrease the efficiency of individual selection in sward and would require a high intensity of selection under no or little competing conditions as maintained in our single-plant experimental design.

To demonstrate that selection for leaf length could be useful for increasing yield under frequent cutting therefore needs to be experimented. In this aim, strong divergent selections have been carried out and the assessment of yield under contrasting cutting frequencies is presently in progress.

\section{REFERENCES}

Burton GW (1974) Recurrent restricted phenotypic selection increases forage yield of Pensacola Bahiagrass. Crop Sci 14, 831-835

Charmet G, Balfourier F, Bion A (1990) Agronomic evaluation of French perennial ryegrass populations: multivariate classification using genotype $x$ environment interactions. agronomie 10, 807-823

Cooper JP, Edwards KJR (1961) The genetic control of leaf development in Lolium. I. Assessment of genetic variation. Heredity $16,63-82$

Edwards KJR, Cooper JP (1963) The genetic control of leaf development in Lolium. II. Response to selection. Heredity 18, 307-317

Falconer DS (1981) Introduction to Quantitative Genetics. Longmann Inc, New York

Hazard L, Ghesquière M, Betin M (1994) Breeding for management adaptation in perennial ryegrass (Lolium perenne L). I. Assesment of yield under contrasting cutting frequencies and relationships with leaf morphogenesis components. agronomie $14,259-266$

Horst GL, Nelson CJ, Asay KH (1978) Relationship of leaf elongation to forage yield of tall fescue genotypes. Crop Sci 18, 715-719

Nelson CJ, Sleper DA (1977) Morphological characters associated with productivity of tall fescue. In: Proc XIII Int Grass/ Cong, Leipzig, Germany, 177-179

Nelson CJ, Asay KH, Sleper DA (1977) Mechanisms of canopy development of tall fescue genotypes. Crop Sci 17, 449-452

Nelson CJ, Sleper DA (1981) Using leaf-area expansion rate to improve yield of tall fescue. $\mathrm{In}$ : Proc XIV Int Grass/ Cong, Lexington, USA, 413-416

Reeder LR, Sleper DA, Nelson CJ (1984) Response to selection for leaf area expansion rate of tall fescue. Crop Sci24, 97-100

Rhodes I (1973) The relationship between productivity and some components of canopy structure in ryegrass (Lolium spp). III. Spaced plant characters, their abilities and relationship to sward yield. J Agric Sci $80,171-176$

Sleper DA, Nelson CJ, Asay KH (1977) Diallel and path coefficient analysis of tall fescue (Festuca arundinacea) regrowth under controlled conditions. Can J Genet Cytol 19, 557-564

Sleper DA and Nelson CJ (1989) Productivity of selected high and low leaf area expansion Festuca arundinacea strains. In: Proc XVI Int Grass/ Cong Nice, France, 379-380

Sugiyama $S$ (1987) Adaptative strategy and its agronomic implications in tall fescue (Festuca arundinacea Schreb). 2 . The relationship between plant type and productivity under the different cultural conditions. Res Bul Univ Farm Hokkaido Univ 25, 43-54

Wricke G, Weber WE (1986) Quantitative Genetics and Selection in Plant Breeding. Walter de Gruyter, Berlin 